\title{
Deciphering the Optimum Doctor-Patient Communication Strategy During COVID-19 Pandemic
}

\author{
Pallvi Kaul ${ }^{1} \cdot$ Deepti Choudhary ${ }^{2} \cdot$ Pankaj Kumar Garg ${ }^{1}$ (D) \\ Received: 2 October 2020 / Accepted: 24 February 2021 / Published online: 5 March 2021 \\ (C) Indian Association of Surgical Oncology 2021
}

"Face is the index of mind."

The old Latin proverb forms the essence of effective doctorpatient communication. Appropriate communication and interpersonal skills enable a doctor to acquire information critical for diagnosis, counselling, providing therapeutic instructions, and establishing a rapport with patients. Information exchange is an essential component of a communication model which incorporates shared decision-making and patient-centred communication. This becomes especially important for doctors involved in providing cancer care, where breaking the bad news is an art to be mastered over time considering the bleak treatment prospects and the stigma associated with the disease $[1,2]$. The current COVID-19 pandemic has strained this vital doctorpatient relationship due to the potential risk of transmission of SARS-CoV-2 infection from each other. Several steps have been recommended to mitigate this risk - wearing a facemask and ensuring physical distance are few of them. However, covered faces are known to interrupt the non-verbal communication which constitutes almost $93 \%$ of our interpersonal communication [3]. Facial expressions are used-voluntarily or involuntarily - to express the emotions; however, facemasks have made it almost impossible for the doctors to use facial expressions, even purloined a smile, to convey our concerns, empathy, and willingness to support to the patients - it poses a challenge to non-verbal communication. Remember, a doctor's facial expressions are usually the first thing a patient notices. A randomised controlled trial highlighted that wearing facemasks by the doctors can result in a significant negative effect on the patient's perception of the doctor's empathy [4]. Furthermore,

Pankaj Kumar Garg

dr.pankajgarg@gmail.com

1 Department of Surgical Oncology, All India Institute of Medical Sciences, Rishikesh, Uttarakhand 249203, India

2 Department of Obstetrics and Gynaecology, All India Institute of Medical Sciences, 249203 Rishikesh, India physical distancing which prohibits proximity and use of haptics (communication using touch) is another potential barrier to non-verbal communication. A gentle pat on the shoulder of the patient or touching her hands by the doctor extends support and empathy. COVID-19 pandemic has, albeit literally, robbed doctors of this opportunity to help build mutual trust with the patient. Another essential pillar of effective patient communication is assessing the state of mind of the patient. Again, the use of facemasks hides the expressions of patients which can serve as useful cues to gauge patients' emotional status and perspectives. Hence, it is also essential for a doctor to have an eagle eye to grasp the subtle signs which may be representative of the patient's state of mind and manifested via the bodily gestures or expressed through the uncovered facial subunits and form a continuous loop of feedback essential for a twoway communication process.

We have adopted the following methods of the non-verbal communications in the current time of COVID-19 pandemic to inspire confidence in the patients and establish doctorpatient rapport. Though all of these ways of communication work in tandem, we have divided them for simplicity.

1. Eye contact: Eyes have been traditionally considered an important tool of non-verbal communication-let eyes speak through their vocabulary. When the facial expressions are almost not visible due to face masks, the importance of eye contact and gaze increases tremendously. A steady eye gaze of the doctor may help her build a relationship of trust with the patient. A shifting gaze or inability to maintain eye contact with the patient will lead to anxiety and mistrust despite constant verbal reassurances provided by the doctor. Eyebrows remain exposed when a patient wears a mask and even a cap; controlled raising or lowering the eyebrows can also do a lot of talking without speaking a word. From the patient's perspective, frequent flinching of eyes, frowning and forehead furrows are an indicator of the degree of pain, though a subjective tool for assessment, yet something not to be overlooked. 
2. Paralinguistics: Facemask does not allow the patients to read the lips. What one wants to communicate is partly through the words that we use and partly though how the words are spoken. Altering the paralinguistics which includes various vocal characteristics - the pitch (the highness or lowness of your voice), volume (how loudly or softly you speak), rate (the speed at which you speak) and voice quality (how pleasant or unpleasant your voice sound) - may help the doctor communicate better with the patients by emphasizing relevant points. Again, the voice modulation at patient's end, e.g. frequent breaks in voice, dismay in tone, use of "Ah", "ooh", intermittent heavy breathing, can be an effective tool to gauge the symptomatology of patient and corroborate with the available findings.

3. Body gestures and movements: Body gestures and movements play a major role in communication by reinforcing or emphasizing the effects of spoken words. A constant back-leaning to lessen the risk of transmission of SARSCov-2 infection would only generate mistrust and a feeling of indifference towards the patient. While ensuring physical distancing, a forward lean while the doctor is sitting at a distance exhibits benevolence and compassion to the patients [5]. Similarly, a frequent head nodding or hand movements convey the patients that the doctor is attentive and actively engaged in the conversation. Shaking hands with the patients is a big "No" in today's time. An Indian style of greeting, the patient with folded hands "Namaste", can be a time-tested gesture of goodwill and compassion. It has already been adopted by the world leaders and eminent persons across the globe, and we do urge the medical community to replace the formal handshake with a "Namaste" until the time the issue of this global pandemic is dealt with. Smile is, perhaps, the first gesture of welcoming someone who visits you.

4. Patient listener: Last but nonetheless, it is important is to become a "patient listener to patients". This becomes particularly important when dealing with terminally ill patients - like the terminally ill patients or patients with locally advanced cancers where the treating oncologist has not much to offer, further constrained by the current pandemic scenario. Once breaking the bad news, the oncologists must remember the "Kubler-Ross model" [6] for the stages of grief and must anticipate the series of emotions experienced by the patient as well as his care-givers. At this point, lending patient an ear to what they have to say is of paramount importance. Amidst the COVID-19 pandemic which mandates strict adherence to the social distancing norms, consoling the patient with a physical touch like - holding hand/arm of the patient, a gentle pat on the shoulder or back is not at all advisable. Some alternative methods to provide compassionate care to the bereaving patient/caregivers are patiently listening to the agony of the patient with frequent head nodding; offering a glass of water and a tissue paper; or suggesting the option of hospice care.

No matter what may come, we, as doctors, are obligated to serve mankind-COVID-19 pandemic is yet another opportunity to resolve our faith and commitment to our noble profession $[7,8]$. In the current time, the routine wearing of facemasks during interaction with the patients is an unavoidable norm, and we have to find ways to circumvent it to boost doctor-patient mutual trust further.

\section{Declarations}

Ethics Approval Not applicable.

Conflict of Interest The authors declare no competing interests.

\section{References}

1. Garg PK (2014) Why do I suffer from cancer? A rhetorical question. Indian J Palliat Care 20(1):64-65. https://doi.org/10.4103/09731075.125572

2. Garg PK (2015) What plagues cancer: does it spread? Oncologist 20(9):1099. https://doi.org/10.1634/theoncologist.2014-0346

3. Benbenishty JS, Hannink JR (2015) Non-verbal communication to restore patient-provider trust. Intensive Care Med 41(7):1359-1360. https://doi.org/10.1007/s00134-015-3710-8

4. Wong CK, Yip BH, Mercer S, Griffiths S, Kung K, Wong MC, Chor J, Wong SY (2013) Effect of facemasks on empathy and relational continuity: a randomised controlled trial in primary care. BMC Fam Pract 14:200. https://doi.org/10.1186/1471-2296-14-200

5. Pensieri C, Delle Chiaie G, Vincenzi B, Nobile L, De Benedictis A, D'Aprile M, Alloni R (2018) Doctor-patient communication tricks. Oncological study at Campus Bio-Medico University of Rome. Clin Ter 169(5):e224-e230. https://doi.org/10.7417/CT.2018.2083

6. Smaldone MC, Uzzo RG (2013) The Kubler-Ross model, physician distress, and performance reporting. Nat Rev Urol 10(7):425-428. https://doi.org/10.1038/nrurol.2013.76

7. Garg PK, Kaul P, Choudhary D, Singh MP, Tiwari AR (2020) Cancer surgery in the era of COVID-19 pandemic: changing dynamics. J Surg Oncol 122:1262-1263. https://doi.org/10.1002/jso.26156

8. Garg PK, Kaul P, Choudhary D, Yendamuri S (2020) Informed surgical consent during the COVID-19 pandemic: exploring the risk of unknown. J Surg Oncol 122:1257-1258. https://doi.org/10.1002/ jso. 26128

Publisher's Note Springer Nature remains neutral with regard to jurisdictional claims in published maps and institutional affiliations. 